University of Wollongong

Research Online

Faculty of Engineering and Information

Faculty of Engineering and Information

Sciences - Papers: Part B

Sciences

2019

\title{
Lubricant as a sticking-scale inhibitor on high temperature sliding contact
}

Hoang Bach Tran

University of Wollongong, hbt943@uowmail.edu.au

Anh Kiet Tieu

University of Wollongong, ktieu@uow.edu.au

Shanhong Wan

University of Wollongong, shanhong@uow.edu.au

Hongtao Zhu

University of Wollongong, hongtao@uow.edu.au

Follow this and additional works at: https://ro.uow.edu.au/eispapers1

Part of the Engineering Commons, and the Science and Technology Studies Commons

Research Online is the open access institutional repository for the University of Wollongong. For further information contact the UOW Library: research-pubs@uow.edu.au 


\title{
Lubricant as a sticking-scale inhibitor on high temperature sliding contact
}

\author{
Abstract \\ Sticking oxide scale is one of the most serious concerns on moving steel surfaces at elevated \\ temperature. However, there has been limited research dedicated to overcoming this issue. In the present \\ work, pin-on-disc testing was carried out to reveal the effects of lubrication on wear characteristics of \\ High Speed Steel sliding against Stainless Steel 316 at $700^{\circ} \mathrm{C}$. Apart from improved friction behavior, the \\ use of inorganic lubricant significantly inhibits material transfer onto the HSS surface which otherwise \\ suffers growing adhered scale during dry sliding contact. In addition, it was found that prolonged \\ exposure to lubrication induces phase transformation of the subsurface iron oxides. The Hematite-to- \\ Magnetite conversion is believed to be a result of complex oxidation and tribological reactions. Multiple \\ characterization techniques were used to thoroughly analyze the worn surfaces, the underlying oxide \\ microstructure and the chemical nature of lubricated interface.

\section{Disciplines} \\ Engineering | Science and Technology Studies

\section{Publication Details} \\ Tran, B. H., Tieu, K., Wan, S. \& Zhu, H. (2019). Lubricant as a sticking-scale inhibitor on high temperature \\ sliding contact. Tribology International, 140 105860-1-105860-11.
}




\section{Lubricant as a sticking-scale inhibitor on high temperature sliding contact}

Bach H. Tran, Kiet Tieu, Shanhong Wan*, Hongtao Zhu*

Faculty of Engineering and Information Sciences, University of Wollongong, Northfields Avenue, Wollongong, NSW 2522, Australia

Corresponding authors: *Shanhong Wan, shanhong@uow.edu.au, *Hongtao Zhu, hongtao@uow.edu.au 


\begin{abstract}
:
Sticking oxide scale is one of the most serious concerns on moving steel surfaces at elevated temperature However, there has been limited research dedicated to overcoming this issue. In the present work, pin-ondisc testing was carried out to reveal the effects of lubrication on wear characteristics of High Speed Steel sliding against Stainless Steel 316 at $700^{\circ} \mathrm{C}$. Apart from improved friction behavior, the use of inorganic lubricant significantly inhibits material transfer onto the HSS surface which otherwise suffers growing adhered scale during dry sliding contact. In addition, it was found that prolonged exposure to lubrication induces phase transformation of the subsurface iron oxides. The Hematite-to-Magnetite conversion is believed to be a result of complex oxidation and tribological reactions. Multiple characterization techniques were used to thoroughly analyze the worn surfaces, the underlying oxide microstructure and the chemical nature of lubricated interface.
\end{abstract}

Keywords: High temperature, oxidation, adhesive wear. 


\section{Introduction}

Hot forming processes account for the most majority production in metal manufacturing, particularly steel-based components. These processes extensively benefit from high-temperature tribology which delivers fundamental understanding of the heated rubbing surfaces followed by potential technical improvements. Under high thermal load, tribological behaviors are generally characterized by high friction and severe abrasive/adhesive wear depending on the nature of mating materials [1-5]. The above concerns can considerably undermine the process efficiency by various means. For instance, excessive friction can lead to seizure while abrasive wear can deteriorate surface quality during hot rolling of steel $[1,2]$. Therefore, there are always demands to tackle the above hindrances and lubrication is among the most practical approaches.

Apart from typical friction/wear concerns, the need of using heat inevitably entails oxidation on the contact surfaces with undesired consequences. The workpieces are generally pre-heated to a definite working temperature prior to the deformation process while the transferred heat also exerts oxidation on the die/roll surfaces. For example, temperature of the steel slab is often in range of $1000-1200^{\circ} \mathrm{C}$ while the roll surface temperature lies between $650^{\circ} \mathrm{C}$ and $750^{\circ} \mathrm{C}$ during hot rolling of steel $[1,3]$. Likewise, the die material is exposed to $600-900^{\circ} \mathrm{C}$ in case of cyclic closed-die forging [6]. Prolonged exposure to high temperature can radically impair overall properties of the roll/die materials. In addition, thermallyinduced oxide scale is considered the primary root from which abrasive/adhesive wear originates $[4,7,8]$. Under high shearing stress, the oxide debris/fragments can be intruded into metal substrate which can initiate cracks and other mechanical failures.

High speed steel (HSS) is a specialized micro-alloyed material with known prevalence in metalworking industry. Combining martensite matrix with primary carbide precipitates (mostly from V, $\mathrm{W}, \mathrm{Mo}, \mathrm{Nb} . .$.$) , the multi-component alloys possess a high hardness and an exceptional wear resistance$ even under extreme conditions. Their applications therefore are widely recognized in hot forming contexts, especially in the make of die/roll in punching, forging, extrusion and sheet rolling [1, 4]. Plenty 
of efforts have been made to evaluate the tribological properties of HSS in various operating conditions. By using a dry rolling-sliding configuration on HSS/carbon steel tribopair, Pellizzari [8] correlated low wear rate of HSS roll with its high hardness while wear mechanism was claimed to be a complex combination of adhesion, abrasion and tribo-oxidation. On the contact surface, formation of an oxide layer was believed to transition friction/wear characteristics into milder regime which otherwise would be severe if direct metal-metal contact occurs. In case of pure sliding contact, transferred oxide scale is also observed on HSS surface when it pairs with mild steel $[9,10]$ and ferritic stainless steel $[11,12]$ at elevated temperature. Pearson et al. [13] revealed the critical role of temperature in the oxidation of mating surface as well as the tribo-sintering tendency of wear debris. Sticking oxide scale is also reported in hot rolling test by thermo-mechanical simulator [14]. It is fairly conclusive that sticking oxide is a widespread concern on high-temperature steel contact that needs to be addressed.

Lubrication expectedly mitigates wear severity by certain mechanism although there has been lack of insight regarding the true nature of those favorable reactions. The present study aims to assess the tribological responses of High Speed Steel/Stainless Steel 316 pair by means of pin-on-disc testing at $700^{\circ} \mathrm{C}$. Wear behavior of HSS pin under the different lubrication conditions is among central considerations. Besides, the effects of lubrication on high-temperature oxidation of the subsurface oxides are also discussed. The chosen lubricant is inorganic sodium borate which can readily provide melt lubrication at elevated temperature $[15,16]$.

\section{Experimental details}

\subsection{Materials preparation}

The present work employs High Speed Steel (HSS) as stationary pin in the friction test since the material is commonly used as the roll/die in hot forming practice [17]. The pins were fabricated out of an industrial roll without heat-treatment. They are wire cut into cylinders then one end is machined by a ceramic tip to achieve a $6.35 \mathrm{~mm}$-diameter hemispherical head with an average roughness of $1 \mu \mathrm{m}$. The multi-alloyed material (nominal weight composition of C: Ni: Mn: Cr: Mo: V: W: Si: Fe = 1.96: 0.78: 
1.26: 4.85: 4.47: 4.00: 3.40: 0.99: remainder) consists of metallic matrix and precipitated metal carbides as shown in Fig. 1a. It is noted that MC simply stands for Metal Carbides since XRD single-handedly is not able to distinguish carbides with different stoichiometry [18]. The corresponding hardness of contributing phases is $8 \pm 0.59 \mathrm{GPa}$ and $19 \pm 3.26 \mathrm{GPa}$, respectively. The two phases can be differentiated by compositional phase mapping in Fig. 1b. A thermocouple was embedded in the HSS pin body to monitor its temperature during the friction test and the measure point is located roughly $2 \mathrm{~mm}$ above the contact surface. Fractional volume of metal carbides is estimated at around 9 12\% (from compositional phase analysis on 3 different locations).
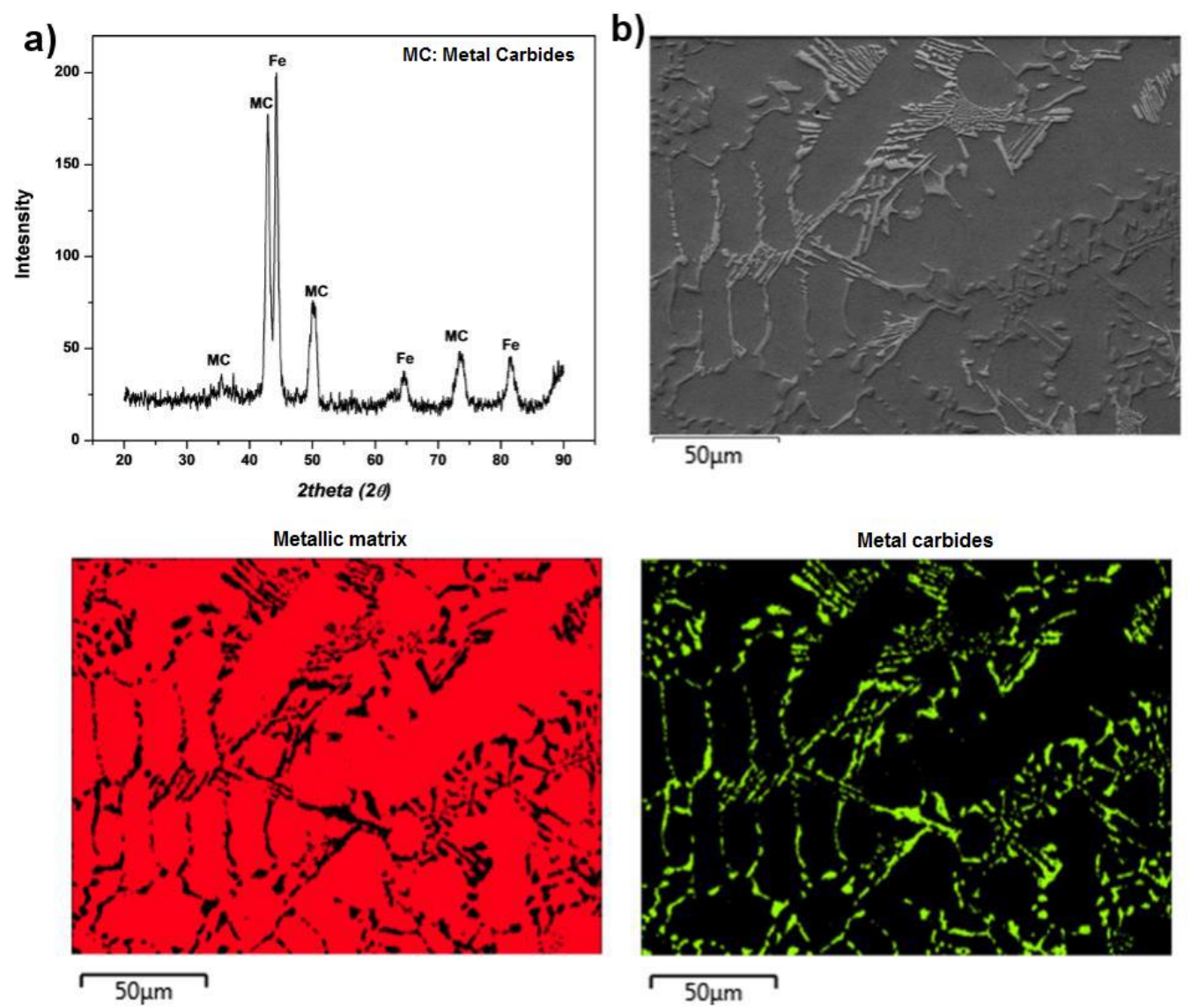

Fig.1: a) X-ray diffraction pattern of HSS, b) Microstructure of polished HSS surface and the corresponding phase map of metallic matrix (1) and metal carbides (2)

Commercial stainless steel (SS316, hardness of $4.3 \pm 0.2 \mathrm{GPa}$ ) was chosen as rotational part in the hot friction test. The round disc is $3 \mathrm{~mm}$ thick with a diameter of $50 \mathrm{~mm}$. Consecutive griding and polishing 
were performed on SS316 disc to achieve an average roughness of $0.1 \mu \mathrm{m}$. Prior to each friction test, the steel pairs were ultrasonically cleaned by ethanol/acetone for contaminants removal.

Crystalline sodium borate $\left(\mathrm{Na}_{2} \mathrm{~B}_{4} \mathrm{O}_{7} \cdot 10 \mathrm{H}_{2} \mathrm{O}\right)$ was chosen as the lubricant for hot friction test. Molecular structure and thermal behavior of sodium borate can be found elsewhere [15]. With a transition point of $520^{\circ} \mathrm{C}$, melt lubrication is readily achieved in the hot friction test. Solution of $5 \%$ weight of lubricant in water was prepared for lubrication test.

\subsection{High-temperature pin-on-disc testing}

Hot friction test was conducted on a UMT2-CETR pin-on-disc tribometer. The disc sample was first placed in the furnace followed by a series of heating sequences to avoid overshooting: $20 \mathrm{mins}$ to $600^{\circ} \mathrm{C}$ and $15 \mathrm{mins}$ to $720^{\circ} \mathrm{C}$. During these stages, the rotation speed was chosen at $5 \mathrm{rpm}$ to ensure uniform heat distribution. Once set temperature is reached, the HSS pin was lowered to a distance of $2 \mathrm{~mm}$ above the SS316 disc surface. HSS pin was oxidized for 10 mins prior to sliding. As illustrated in Fig. 2, temperature of the pin sharply rises after the first 5 mins followed by stabilization at $695^{\circ} \mathrm{C}$. Engagement of the steel pair further increases HSS surface temperature to nearly $700^{\circ} \mathrm{C}$. In the present study, heating program was manipulated to represent actual working condition in which HSS surface temperature typically lies between $650^{\circ} \mathrm{C}$ and $750^{\circ} \mathrm{C}$ during hot forming processes $[1,10]$. Lubricant solution was dropped onto the hot disc 2 mins at a rate of $0.01 \mathrm{ml} / \mathrm{s}$ prior to sliding. Linear sliding velocity was kept at $0.096 \mathrm{~m} / \mathrm{s}$ with two different durations: $5 \mathrm{mins}$ and $15 \mathrm{mins}$. The normal load was fixed at $5 \mathrm{~N}$ corresponding to $0.78 \mathrm{GPa}$ maximum Hertzian contact pressure. When friction test stops, the HSS pin was immediately retrieved from the furnace to avoid further oxidation. Friction coefficient evolution was also recorded while at least 3 tests were performed at each condition to ensure the repeatability. 


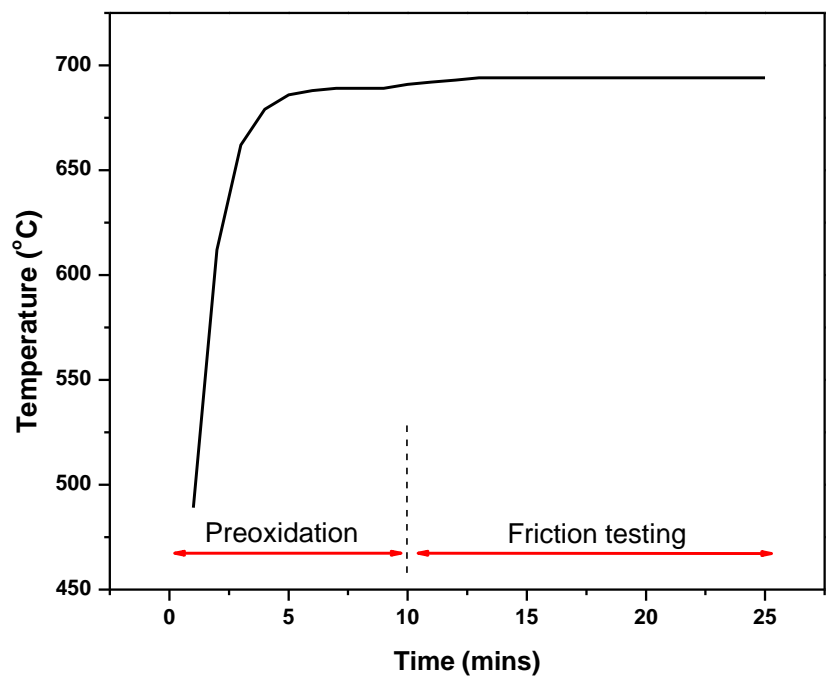

Fig. 2: Temperature record of HSS pin during pre-oxidation and friction test

\subsection{Characterization}

X-ray Diffractometer (GBC MMA) with $\mathrm{Cu}-\mathrm{K} \alpha$ source and a step size of $0.02^{\circ}$ was used to determine crystal structure of the HSS material. The operating voltage and current of the X-ray were selected at $35 \mathrm{kV}$ and 28.6mA, respectively. An Atomic Force Microscopy (Digital Instrument Dimensions 3100) was used to generate height profiles of the polished HSS substrate. Worn morphologies on HSS pins were captured by a 3D Interferometer Optical Microscope (Bruker Contour GT-K). Hardness of steel tribopairs was measured by a Hysitron Triboindenter using a Berkovich probe (150nm-diameter tip) with a maximum load of $5000 \mathrm{uN}$.

Morphologies of the worn surfaces were further examined by a Dual Beam FEI Helios NanoLab G3 CX (FIB-SEM) equipped with Energy Dispersive Spectroscopy (EDS). In addition, ion milling was also conducted in this instrument to prepare STEM specimens. At a tilted angle of $54^{\circ}$, cross-sectional views of unlubricated HSS pins were exposed by consecutive ion milling. Prior to targeted milling, a thin layer of Pt was deposited on the region of interest to prevent beam damage. In case of STEM specimen prepration, thin foils were lifted out from the region parallel to sliding direction and constantly kept in the vacuum chamber to avoid contamination. Cross-sectional observations of the lubricated interfaces were 
accomplished by an aberration-corrected JOEL ARM 200F Scanning Transmission Electron Microscopy (STEM) at $200 \mathrm{keV}$. The microscope is equipped with SDD EDS detector which allows elemental mapping with atomic resolution. In elemental phase mapping, comparison of X-ray spectrum between pixels is made and those with similar statistic are collated into one specific phase. Selected Area Electron Diffraction (SAED) was performed on the FIB lamellas at multiple points and three representatives are reported. All the calibrated diffraction patterns were processed by a suit of software tool (DiffTools) in Digital Micrograph, a widely-known platform software for TEM images processing [19, 20]. Intensity profiles as a function of reciprocal distance were then derived, normalized and compared between different testing conditions. Referenced d-spacings of relevant crystallites were collected from Powder Diffraction Files 4+ 2018.

\section{Results}

\subsection{Microstructural evolution of HSS at high temperature and its tribological behaviors against SS316}

Since HSS is composed of two different phases, their individual oxidation behaviors at high temperature collectively contribute to the overall properties of the sliding surface. It has been acknowledged that oxidation of metal carbides are more thermodynamically favorable due to low energy barrier [18, 21]. Carbide-free matrix is subsequently oxidized with the development of iron oxides. XRD pattern of oxidized HSS substrate at $700^{\circ} \mathrm{C}$ for 10 mins reveals the major formation of $\mathrm{Fe}_{2} \mathrm{O}_{3}$ and a minor fraction of $\mathrm{Fe}_{3} \mathrm{O}_{4}$ (Fig. 3c). AFM images (Fig. 3a, b) clearly illustrate superior growing kinetic of metal carbides than that of metallic matrix upon high temperature oxidation. Nevertheless, it is expected that the native oxide scale from metallic matrix plays a critical role on the contact interfaces due to their dominating proportion in the starting material. 

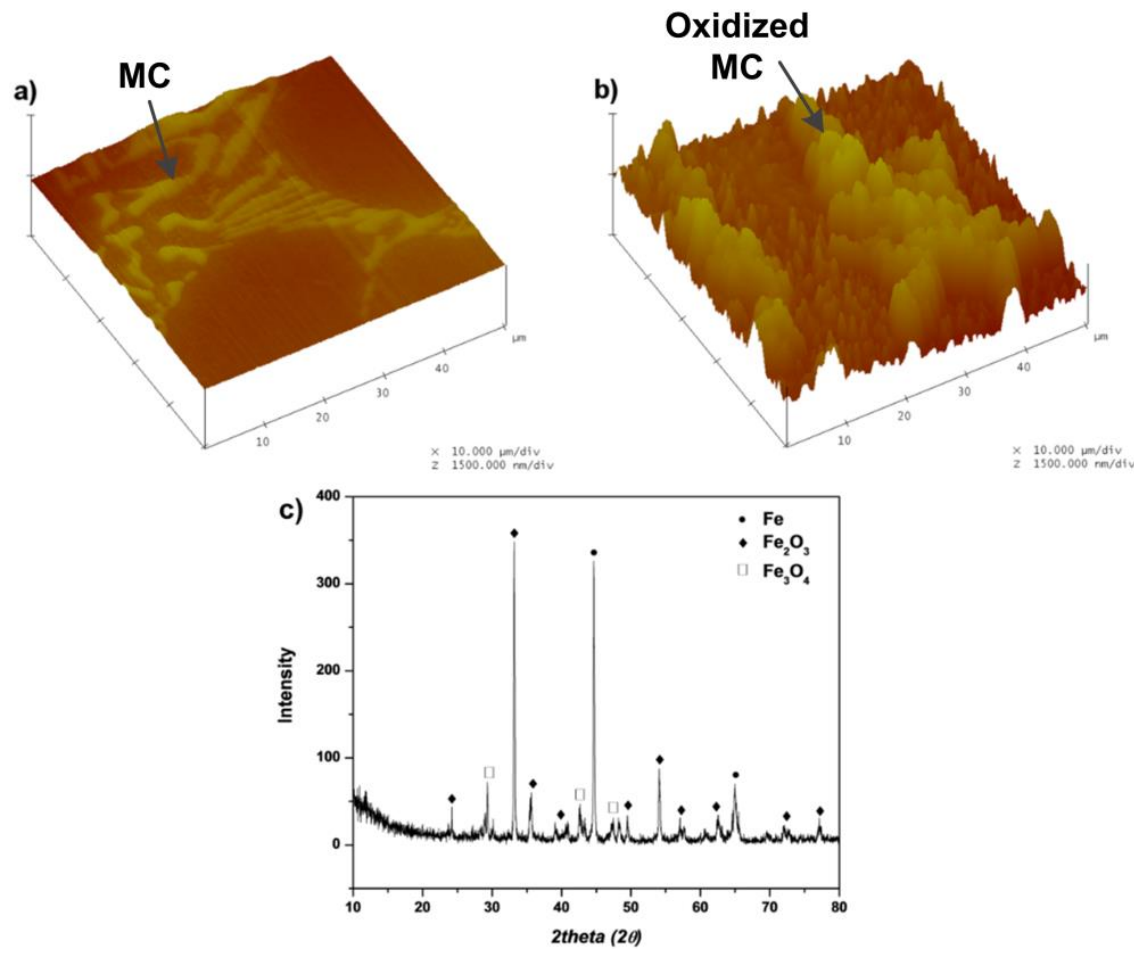

Fig. 3: AFM image of HSS specimen before (a) and after oxidation (b) at $700^{\circ} \mathrm{C}$ for $10 \mathrm{mins}$,

(c) XRD pattern of the oxidized HSS

Friction coefficient curves generated from HSS/SS316 sliding contact are given in Fig. 4. Under lubrication-free condition, it can be seen that friction coefficient fluctuates widely between 0.4-0.9 at the first 400 seconds before stabilizing at an average value of $0.23 \pm 0.05$. During the running-in period, high friction coefficient is likely attributed to contact between hard metal oxides [12]. On the other hand, the following steady stage indicates potential formation of tribolayer with friction-reducing effect. It is evident in Fig. 5 where transferred material on HSS pin is observable on both unlubricated tests, regardless of testing duration. At 5mins mark (Fig. 5b), the worn morphologies are characterized by plateau build-up and progressive smearing of the adhered layer. As sliding test continues, the contact area enlarges with apparent flattening effect which consequently reduces the contact pressure. The complete 
formation of the tribo-bed significantly alleviates wear severity which can be indicated by smooth rubbing surface with the only damage being minor fracture in the sub-surface region (Fig. 5d).

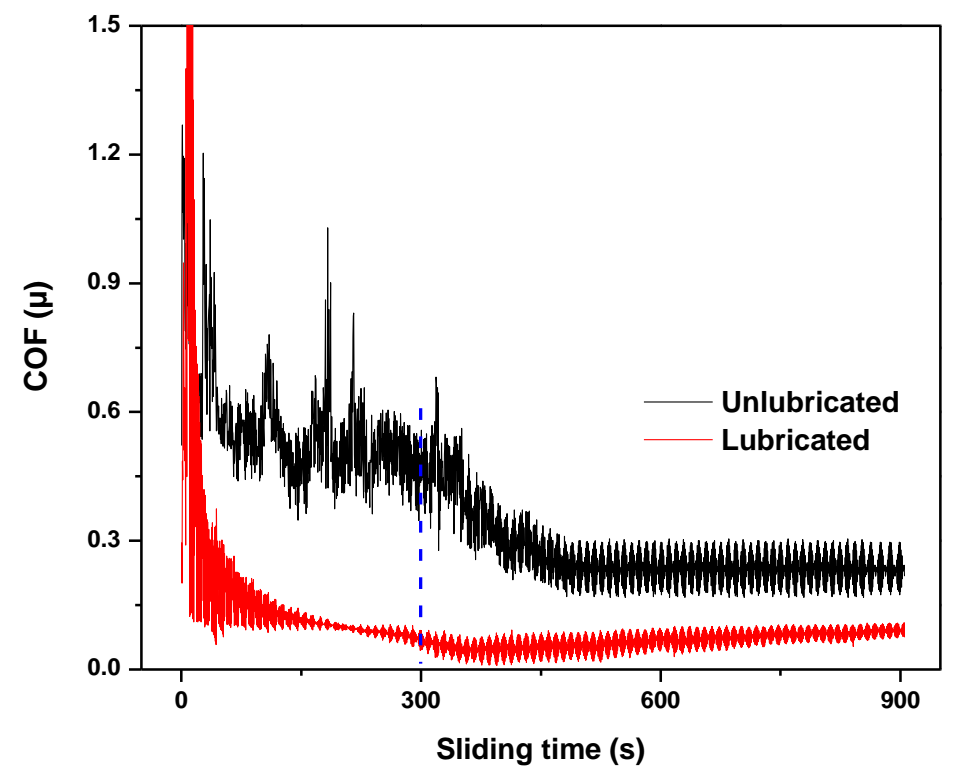

Fig. 4: Friction coefficient curves from HSS/SS316 tribopair with and without lubrication

a)

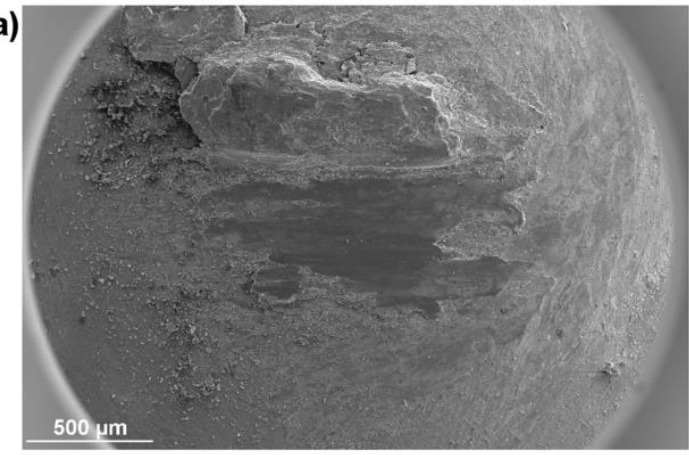

c)

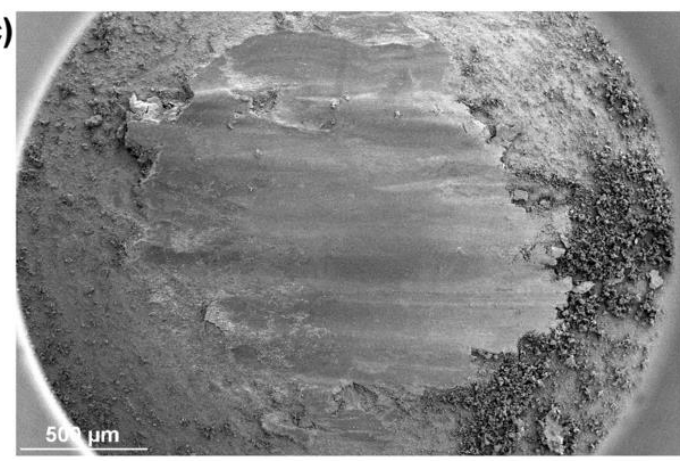

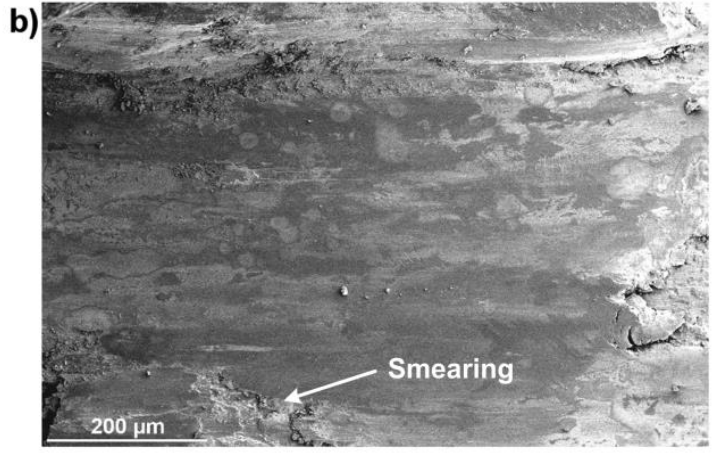

d)

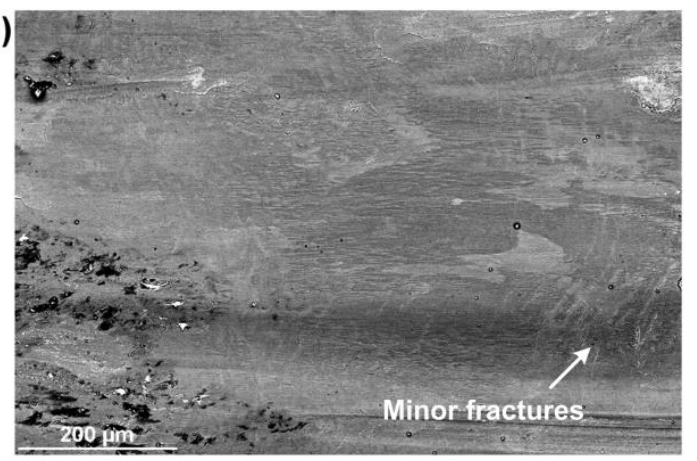


Fig. 5: Worn morphologies of HSS pin without lubrication after 5 mins (a, b) and $15 \operatorname{mins}(\mathrm{c}, \mathrm{d})$

Fig. 6 illustrates cross-sectional views of HSS worn surfaces along with relevant elemental mapping after dry sliding tests. After 5mins, by contrast difference, the transferred layer can be distinguished from the HSS substrate which is characteristically filled with carbides chunks (Fig. 6a). The transferred layer thickness ranges from 4.5 to $6.6 \mu \mathrm{m}$ at 5 mins mark then it soars to roughly $34 \mu \mathrm{m}$ (Fig. 6b) as sliding duration triples. Oxygen signal indicates that the adhered material is predominantly composed of oxides. However, there could be inclusion of stainless steel debrises (from the disc) in the transferred layer, although they were likely oxidized as the test progresses. It is noteworthy that the tribo-oxide layer is exclusive of any sign of carbides implying the foreign nature of transferred material. Although the native oxide scale developed during pre-oxidation accounts for a definite fraction of the received scale, it is conclusive that transferred (and adhered) oxide scale is the most dominating wear occurrence on HSS surface sliding against SS316.

a)

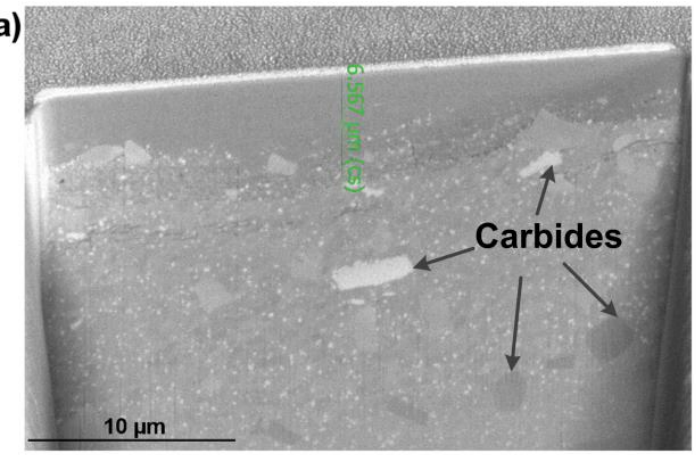

Fe $L$ series

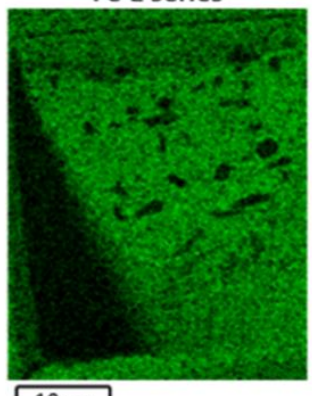

$\longdiv { 1 0 \mu m }$

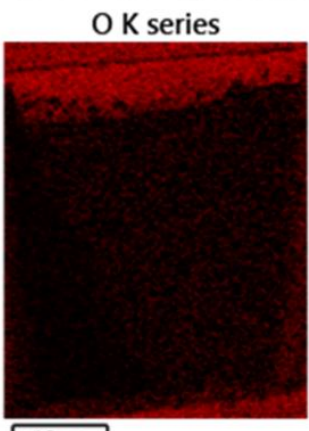

$\longdiv { 1 0 \mu \mathrm { m } }$ b)

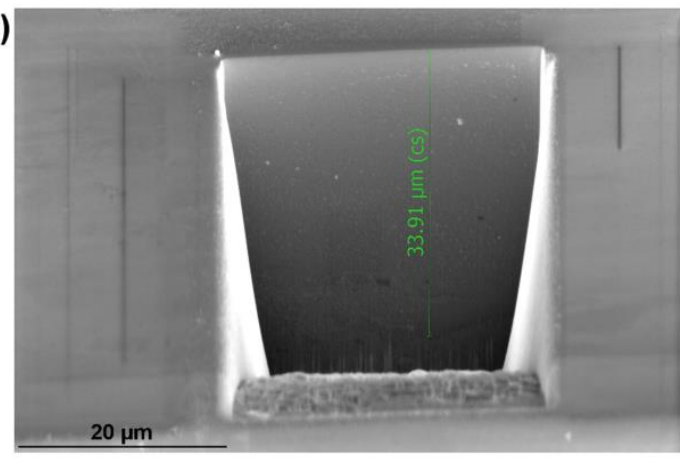

$\mathrm{O} \mathrm{K}$ series

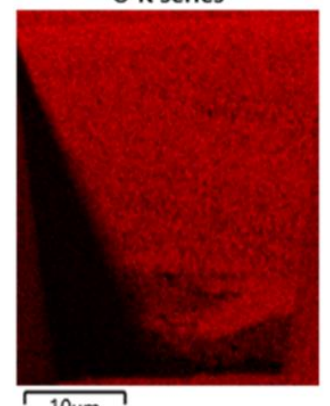

Fe L series

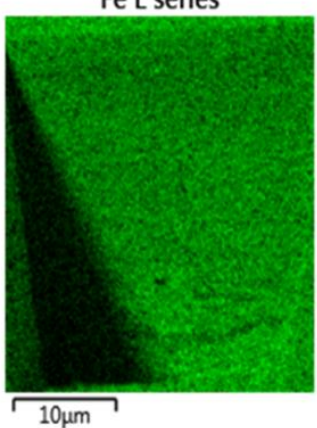


Fig. 6: Cross-sectional views of HSS worn surfaces without lubrication after

a) 5 mins and b) $15 \mathrm{mins}$ (specimens were tilted at $54^{\circ}$ )

\subsection{Effect of lubrication on tribological behavior of HSS pin}

As shown in Fig. 4, frictional behavior of HSS/SS316 sliding contact substantially benefit from lubrication. The use of melt lubricant clearly shortens running-period, as friction coefficient enters stabilization stage roughly after 200 seconds of sliding. The downward trend could be associated with the gradually decreasing shearing stress by the presence of the lubricant melt on the contact surface. In addition, the average friction yields at only $0.1 \pm 0.02$ during steady period which is reduced by 2.3 times in comparison to lubrication-free case. Fig. 7 displays SEM micrograph of HSS pin surface after 5minslubrication test while the one after 15 mins-test is not given due to similarity. Worn morphology reveals no major damages but only a few scratches along sliding direction. Supporting EDS spectrum exhibits intense signals of lubricant elements including $\mathrm{B}, \mathrm{O}$ and $\mathrm{Na}$ with relatively weak peak of Fe suggesting a layered structure in which lubricant film resides on iron oxide base.
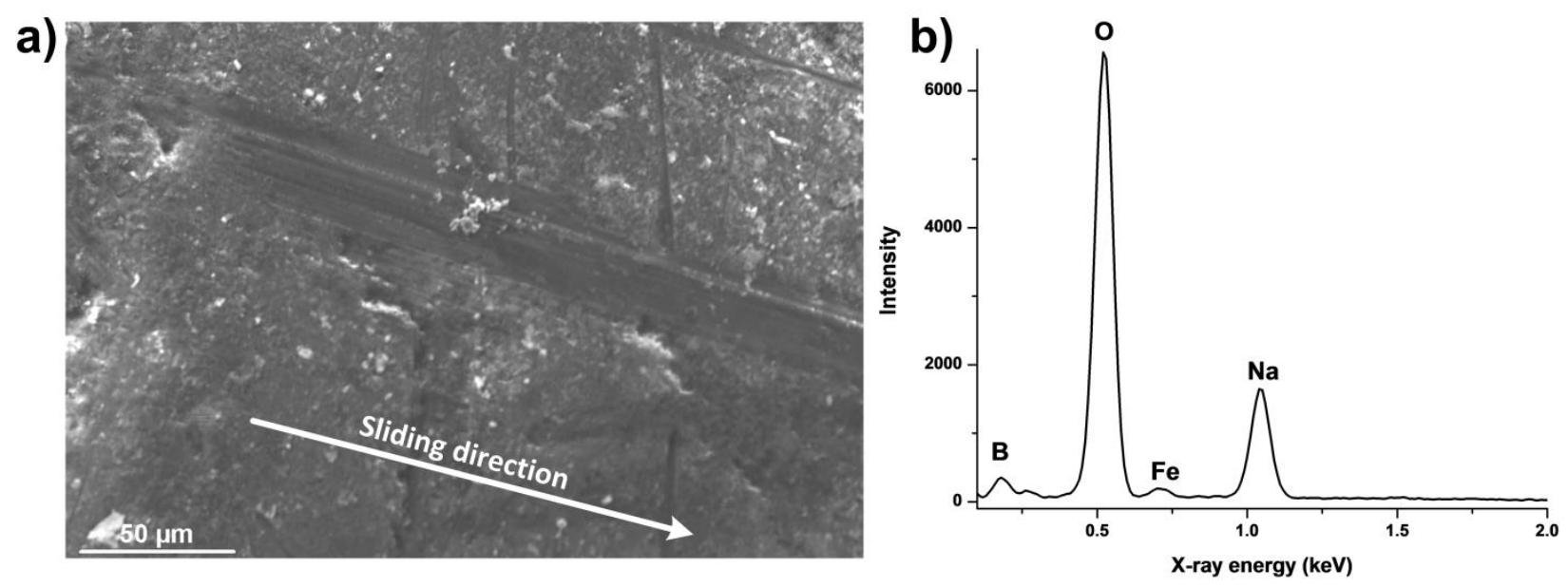

Fig. 7: Worn morphology of HSS pin in lubrication test after 5 mins (a) and EDS spectrum (b).

In order to unfold the immediate sliding interface, cross-sectional observations of HSS pins exposed to lubrication are given in Fig. 8. By contrast difference, it can be seen that there are 3 distinct layers 
corresponding to lubricant film, oxide scale and HSS substrate as denoted in each image. In case of 5mins test, it is clear that the oxide scale is composed of nanoparticles with dimension of $\sim 20-100 \mathrm{~nm}$ (Fig. 8a). Apparent grain refinement can be found on topmost region while coarsening is evident at the scale/substrate boundary. The oxide structure remains remarkably compact with no sign of cavities or pores. In addition, the scale has an average thickness of $0.65 \mu \mathrm{m}$ which is approximately 10 times lower than what observed in case of lubricant-free test. There are signs of slight tearing damages in the HSS substrate which likely happened during the running-in process. As sliding time increases, the scale on HSS thickens to approximately $6 \sim 6.5 \mu \mathrm{m}$ with some microstructure changes (Fig. $8 \mathrm{~b}$ ). However, it is still significantly thinner than that observed in dry sliding counterpart (which is approximately $34 \mu \mathrm{m}$ ). It is noteworthy that the immediate oxide/lubricant interface appears fairly smooth despite experiencing high local pressure during the friction test. Also, extended exposure to lubrication seems to result in increasing degree of pores and voids among oxide grains (Fig. 8b).
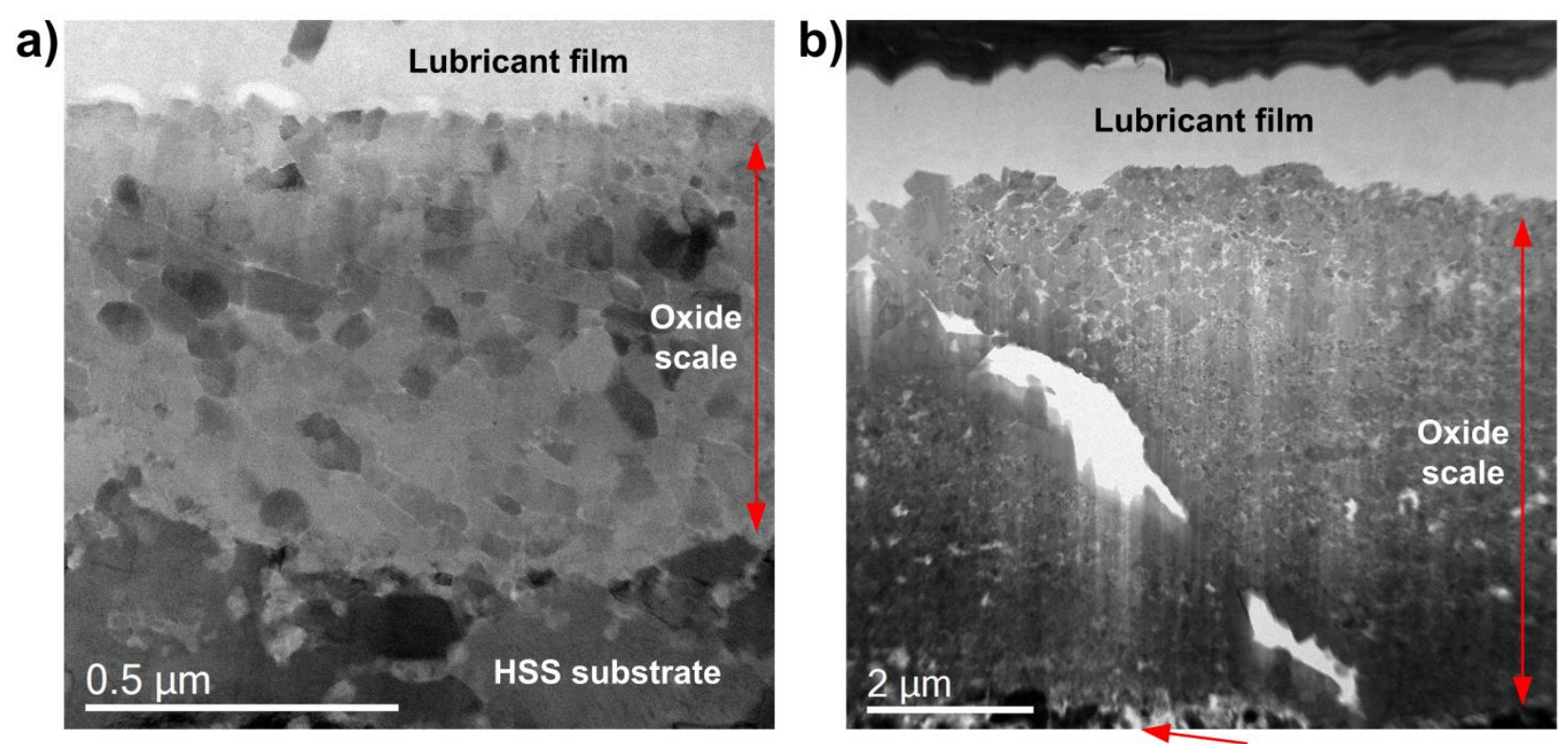

HSS substrate

Fig. 8: STEM-BF images of cross-sectional HSS pins after lubrication test

a) $5 \mathrm{mins}$ and b) $15 \mathrm{mins}$ 
Apart from friction-reducing effect, it is evident that borate lubrication inhibits sticking oxide scale on HSS surface reflected by the oxide thickness reduction. After lubricant removal, 3D profiles of HSS pin are given along unlubricated counterparts for worn morphology examination (Fig. 9). In contrast to the apparent material transfer during dry sliding (Fig. 9a, b), HSS pins practically shows no sign of adhered material across the whole contact areas exposed to lubrication (Fig. 9c, d), although some damages are visible in the longer test. Closer examination reveals craters produced in FIB work, mostly on top region of the worn area where oxide scale thicknesses were extracted.

a)

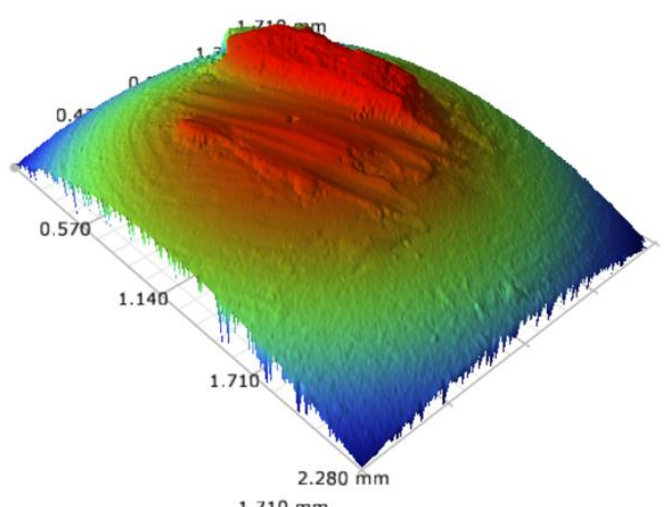

c)

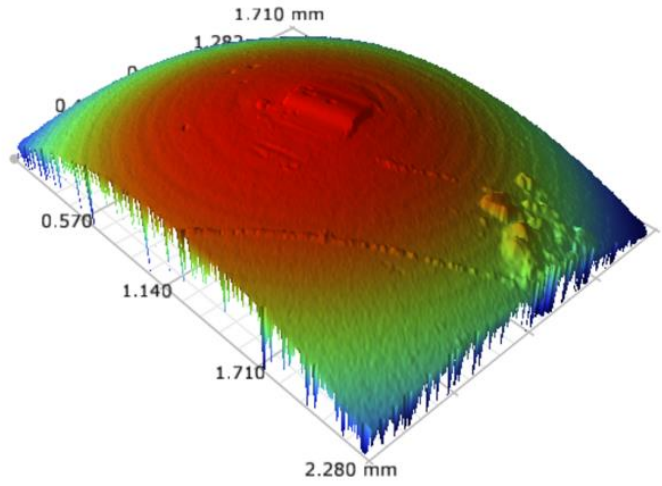

b)

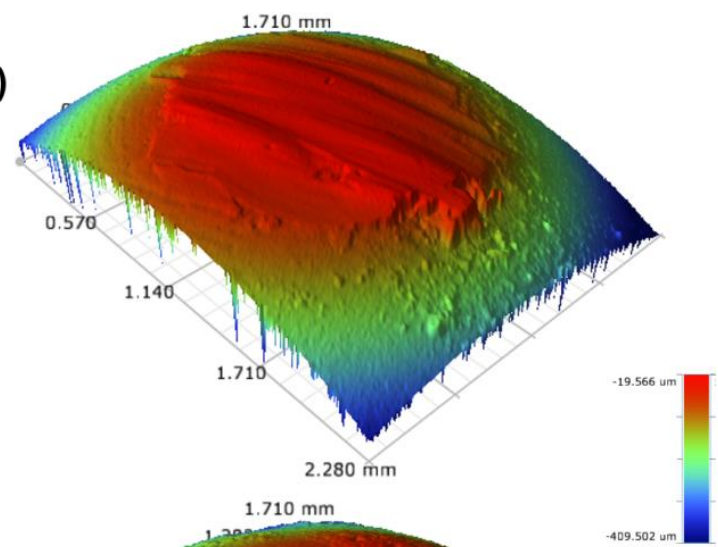

d)

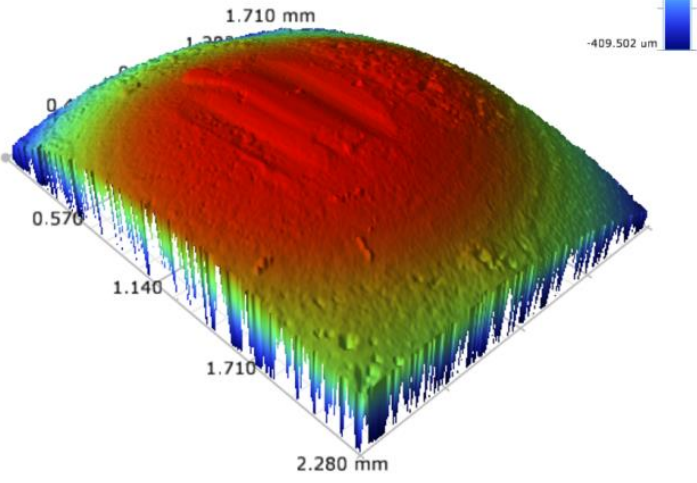

Fig. 9: 3D profile images of HSS pin after dry sliding test (a-5mins, b-15mins) and lubrication test (c-5mins, d-15mins)

\subsection{Effect of lubrication on iron oxides microstructure}

It is expected that the presence of lubricant film can exert certain influences on the high-temperature oxidation behavior of the underlying oxide scale. Fig. 10 shows cross-sectional TEM micrographs of HSS surface under different lubrication/oxidation conditions. Electron diffraction was performed on the FIB 
lamellas and the processed intensity profiles are also provided to determine the crystal structure of iron oxides. In case of 5mins lubrication test, it is clear that the oxide scale is composed of sub-micron particles with major constituent being Hematite $\left(\mathrm{Fe}_{2} \mathrm{O}_{3}\right)$ (Fig. 10a). As sliding times triples, there emerges a phase evolution as Magnetite $\left(\mathrm{Fe}_{3} \mathrm{O}_{4}\right)$ (mostly (102), (200) and (016)) replaces Hematite to become the most dominant phase as evidenced in the adjacent profile. Similar analysis routine was accomplished on purely oxidized HSS, which was extracted from non-contact area after $15 \mathrm{mins}$ lubrication test (Fig. 10c). As can be seen, there are 3 layers in top-to-bottom order: Pt cap, oxide scale and HSS substrate with presence of carbides precipitates. The oxide layer thickness varies from 1 to $2 \mu \mathrm{m}$ across the whole lamella while scale is largely composed of Hematite with a minor fraction of Magnetite as evidenced in the complementary profile. This aligns quite well with X-ray diffraction result (Fig. 3c). Chromia (110) $\left(\mathrm{Cr}_{2} \mathrm{O}_{3}\right)$ is also present in a fair amount which likely concentrates on scale/substrate interface [21, 22].

The phase transformation over sliding time is further substantiated by the morphology change of iron oxide particulates. Fig. 11 exhibits magnified TEM micrographs of oxide scale formed under lubrication after increasing sliding durations. It can be seen that the iron oxide nanograins (with average dimension $<100 \mathrm{~nm}$ ) appear to have poly facets when exposed to shorter lubrication test (Fig. 11a). This could be the cause of highly compact scale as individual grain can accommodate geometry changes from the surrounding with ease, especially under the effect of shearing. The oxide grains from static oxidation test resemble the one achieved from 5mins lubrication test. On the other hand, prolonged exposure to lubrication evidently leads to shape transformation as the oxide nanoparticles exhibit an unambiguous cubic morphology (Fig. 11b). The nanocubes seem to be geometrically distorted as a result from tribological effect. Fig. 11c illustrates a typical cubic oxide particle with sharp edges and indicative dspacing of Magnetite (102). The Magnetite nanoparticles of with such characteristic shape are found across the whole scale. Contrary to a compact scale observed at shorter test, the loose oxide scale with emerging voids and porosity can be attributed to the apparent phase transformation under extended sliding duration. 

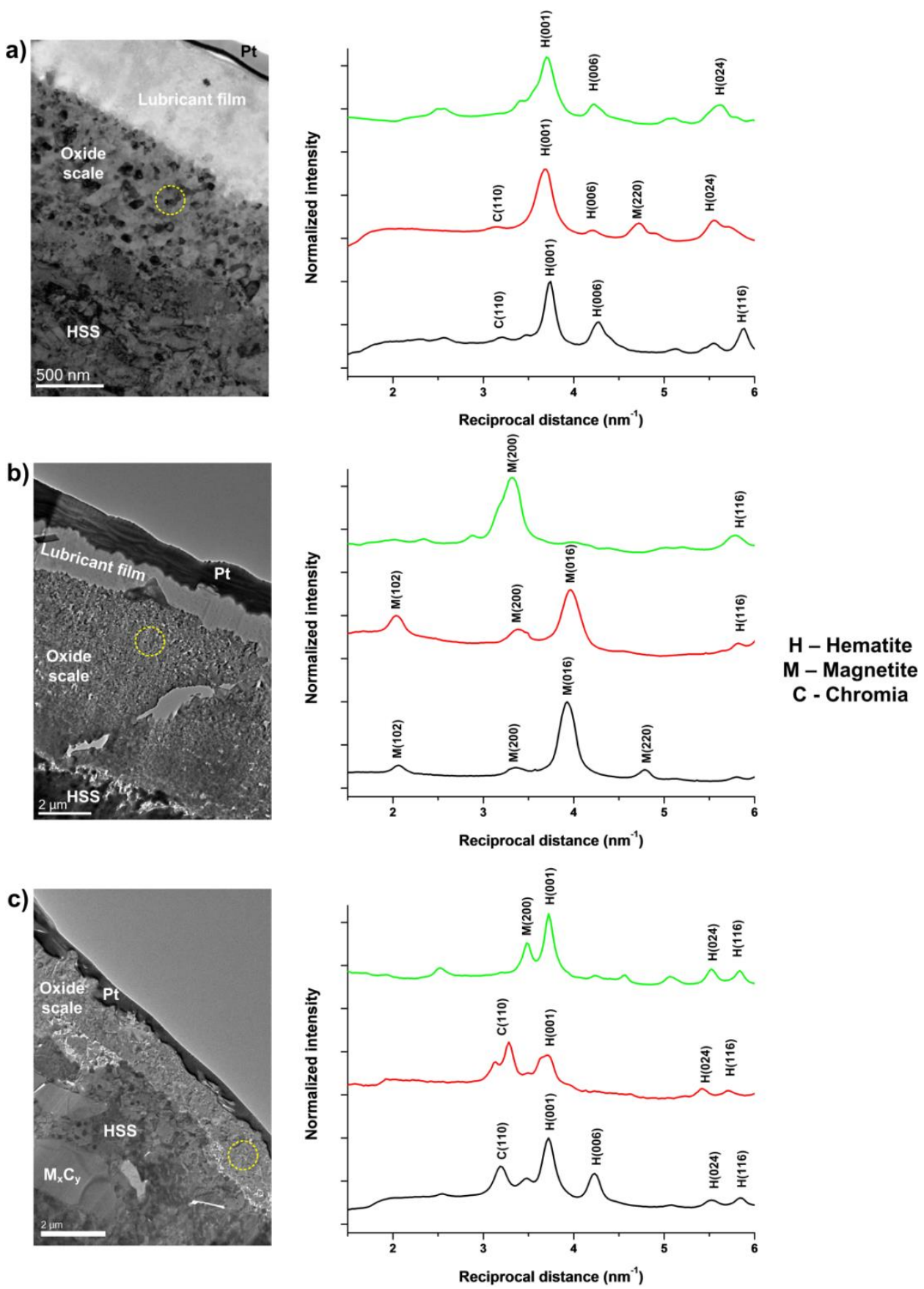

Fig. 10: TEM images of HSS pin cross sections in a) 5mins lubrication, b) 15mins lubrication and c) 15 mins static oxidation with corresponding intensity profiles from SAED 

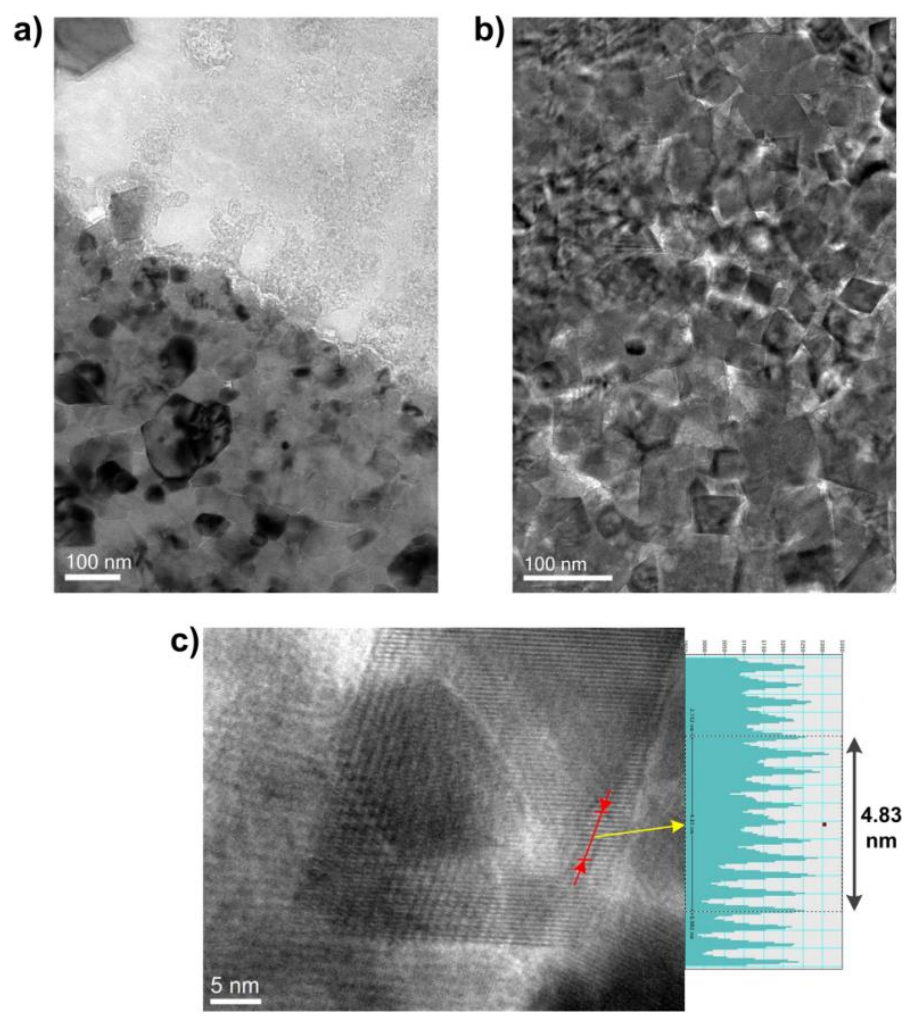

Fig. 11: Magnified oxide microstructure after lubrication tests, a) 5mins, b) $15 \mathrm{mins}$ and c) $\mathrm{Fe}_{3} \mathrm{O}_{4}(102)$ nanoparticle with indicated d-spacing

\section{Discussion}

At elevated temperature, oxidation of steel occurs invariably in open atmosphere which manifests in a growing oxide scale. The onset temperature is a function of steel chemistry as alloying elements can be introduced for enhanced oxidation resistance (but generally around $570^{\circ} \mathrm{C}$ [23]). Under tribological exposure, the oxidation reaction may occur at lower temperature due to frictional heat induced by asperity contacts and plastic deformation which can significantly raise local temperature [24, 25]. For instance, Pearson [13] demonstrated formation of oxidized debris bed on high-strength alloy steel from $150^{\circ} \mathrm{C}$ during fretting contact. In the current work where the mating pair was pre-oxidized, sliding mechanics mainly concern oxide-oxide contacts. Mechanical attributes of the grown oxides such as hardness, plasticity and in some extent grain size therefore become the governing factors of wear and frictional behaviors. 

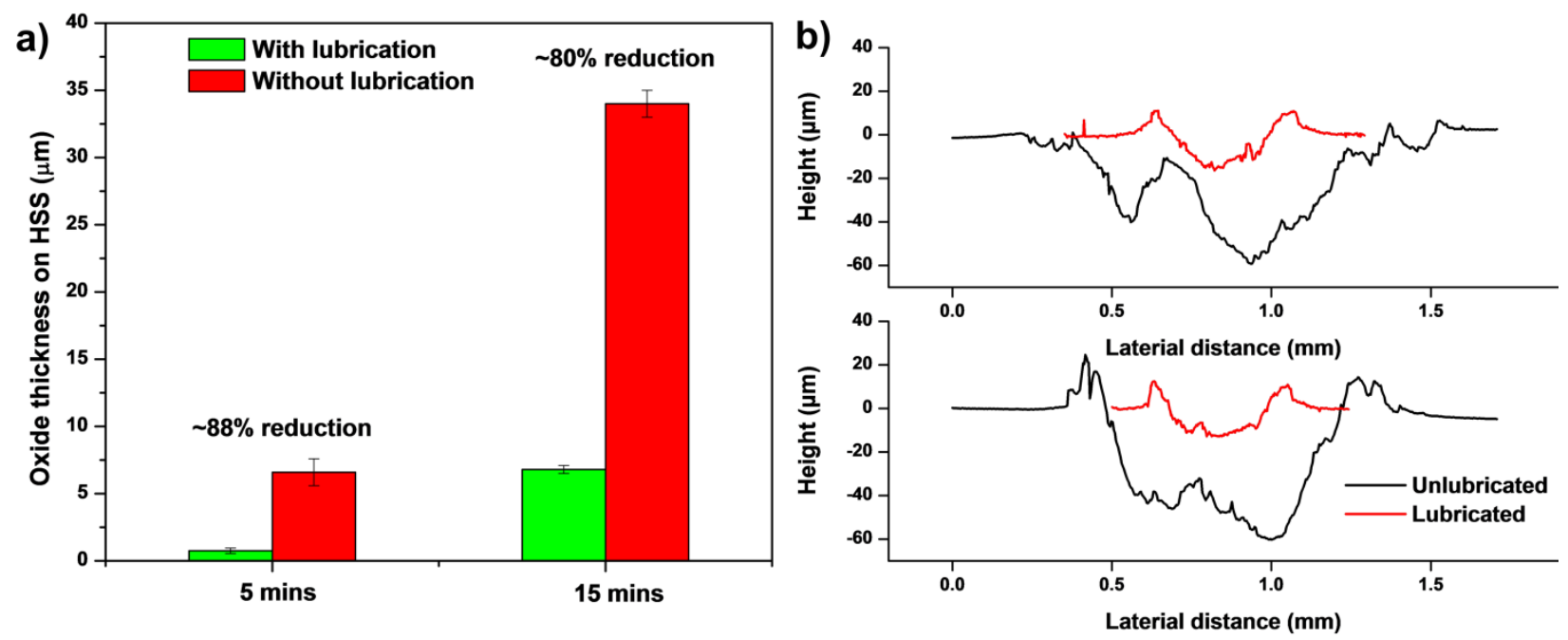

Fig. 12: a) Variation of oxide thickness on HSS pin with various lubricating condition and b) wear track profiles on SS316 disc after 5mins (below) and 15mins (above) test

It has been shown previously (Fig. 3) that carbides oxides are present on the pre-contact surface of oxidized HSS alongside iron oxide matrix. However, despite protruding through the oxide scale, those carbides oxide particles are likely to be ejected upon contact due to their poor adherence with the underlying substrate. This is justified by the total absence of carbides oxides on the sliding surface from cross-sectional observation (Fig. 6). The current work is in good agreement with past literature. By studying oxidation behaviors of HSS at high temperature under dry and wet atmosphere, Qiang et al. [21, 22] observed various types of carbide oxides (mostly V-based) that are loosely held on top of a more compact scale. After conducting friction test against mild-steel, there was no sign of carbide-based particles on the front most contact area [10]. On the other hand, the native oxide matrix is able to withstand high shearing stress due to their excellent deformability and strong bonding with metal substrate, mostly through the formation of anchoring $\mathrm{FeCr}_{2} \mathrm{O}_{3}$ spinels $[18,21,22]$. 
a)
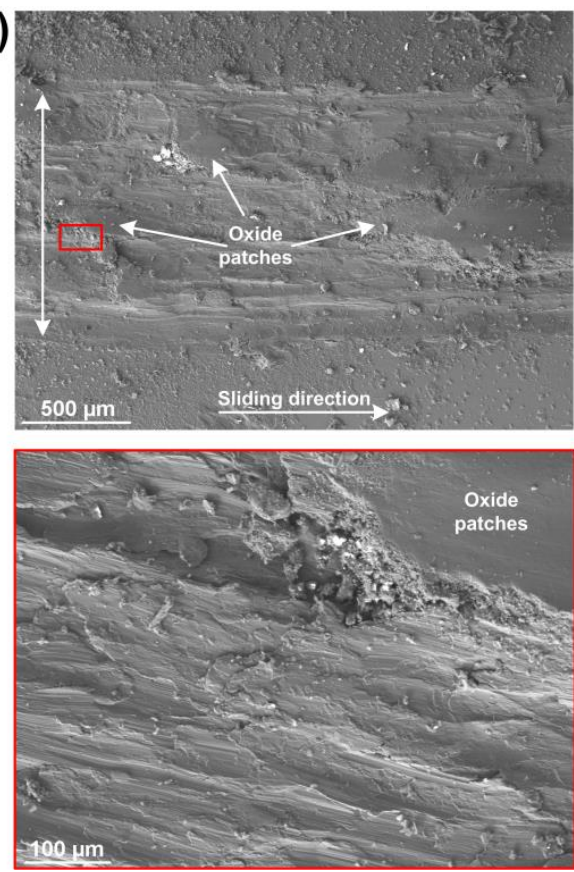

b)
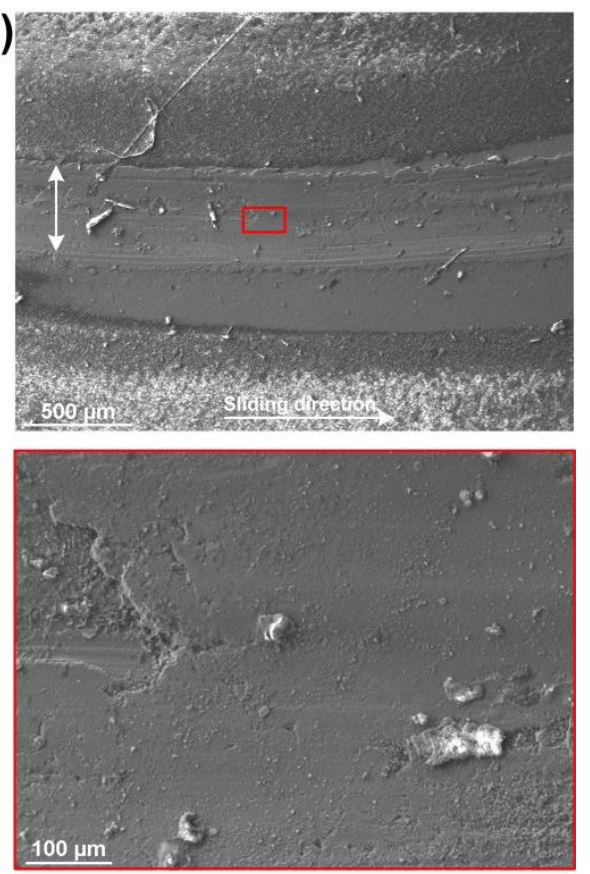

Fig. 13: Worn morphologies of SS316 disc after 15mins test, (a) without lubrication and (b) with lubrication (below are magnified images, double-arrowed line indicates track width)

Formation of the tribo-bed (Fig. 5 and 6) is likely originated from combined effects of adhesive wear, particles sintering and tribo-oxidation [13]. Development of such layer is largely dominated by microstructural characteristics of the involving oxide particles while its endurance is also a function of loading amplitude and sliding velocity. Previous studies on sliding HSS/mild steel pair revealed tribooxide layer formation and its subsequent disintegration $[9,10,26]$. Particle omission by spallation leads to intermittent coverage of the glaze layer and increases friction coefficient as a result. This might arise from the fact that iron oxides tend to grow into coarse particles with poor deformability on mild steel which undermines the tribo-layer formability. In contrast, finer oxide particles are proven to accelerate the tribo-bed formation on sliding surface [27]. Native oxides of highly-alloyed steel reportedly grow in form of nano-scale grains $[28,29]$. Herein, oxide scale grown on SS316 [16] are reportedly composed of nanosized oxide grains favouring robust establishment of the glaze layer. The consolidation rate of the tribobed is believed to outweigh the omission rate of debris particles indicated by the growing thickness of glaze layer over time (by nearly 6 times as sliding time extends from $5 \mathrm{mins}$ to $15 \mathrm{mins}$ ). Although the 
presence of tribolayer is commensurate with friction-reducing and -stabilizing effects, it is still considered unfavorable as it is developing at the expense of sacrificial wear of the opposing surface.
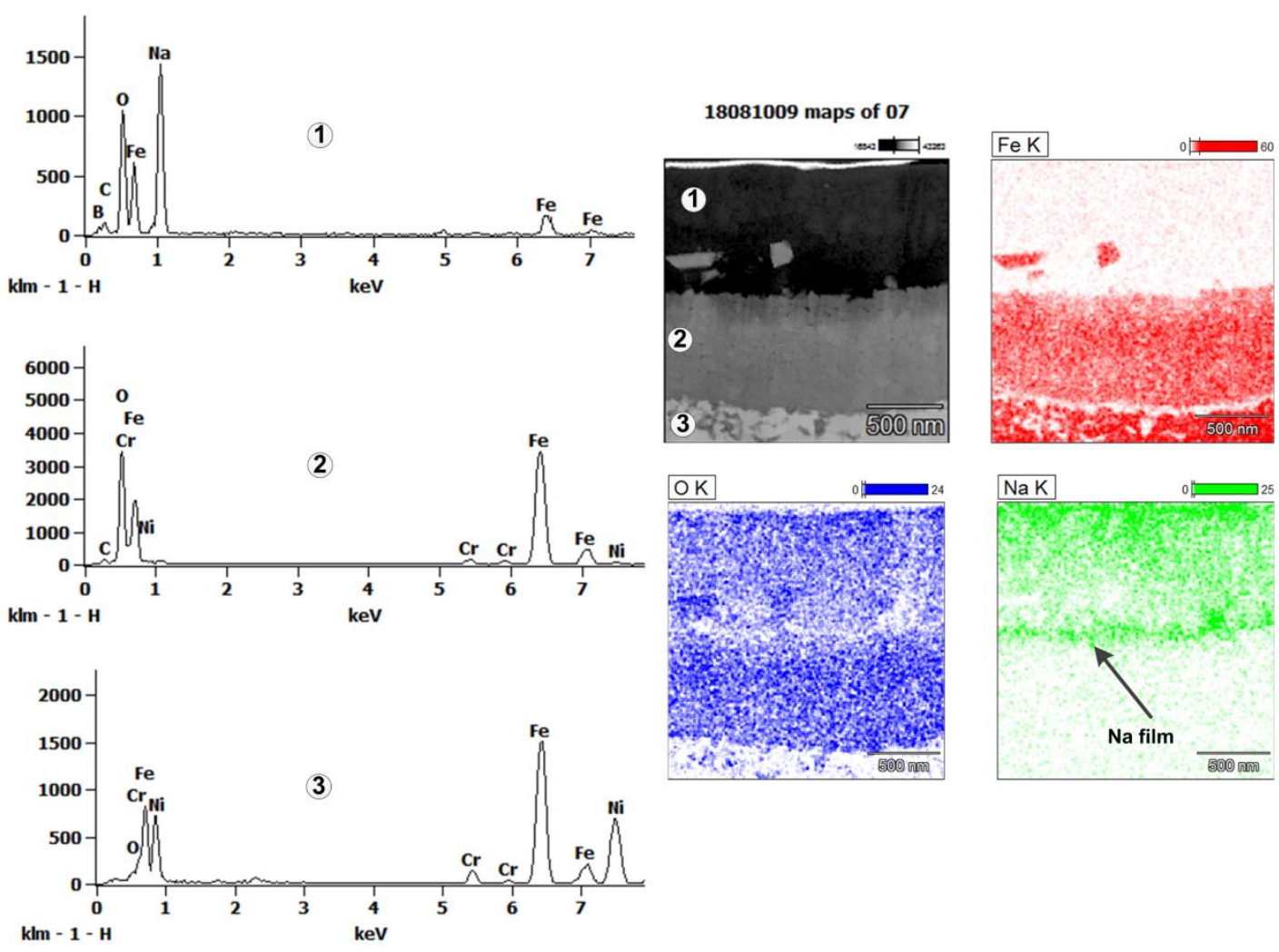

Fig. 14: Individual phase spectrum and elemental distribution across the lubricated HSS pin after 5mins test

It is obvious that the employment of borate melt markedly inhibits adhered/transferred material on HSS pin as shown by the reduced scale thickness (Fig. 12a). The total reduction rate is estimated at $\sim 88 \%$ after 5 mins and $\sim 80 \%$ after 15 mins compared to unlubricated counterparts. In addition, the suppressed adhesive wear on HSS surface is indicative of lesser material loss on the opposing SS316 disc (Fig. 12b) with maximum reduction of $76 \%$ compared to unlubricated case. The exceptional wear resistance of borate lubricant is regarded as the most principle factor in the causation of anti-sticking behavior. Material transfer fundamentally occurs when there emerges either wear debris or third-body object on the contact interface. A reduced wear rate on the disc (evident in Fig.12) practically means less scale-sticking probability. Worn morphologies of SS316 disc after 15mins tests are given in Fig. 13 to justify the wear 
mechanism under different lubrication conditions. In the absence of borate lubricant, catastrophic damages are visible including ploughing, abrading coupled with formation of discontinuous oxide patches. In contrast, borate lubrication induces negligible wear severity as indicated by a reduced track width alongside a smooth worn surface (Fig. 13b). It is noted that SEM micrograph was captured after lubricant removal to reveal the true surface morphology.

Beside friction-reducing effect (Fig. 4), the resistance against adhered wear arises from effective lubrication and it is believed that the tribofilm plays a core role in these desirable behaviors. Surface chemistry of the immediate sliding interface is further examined to reveal the lubrication mechanism. Fig. 14 shows cross-sectional view of lubricated HSS interface after 5mins sliding test alongside relevant phase and elemental mapping. There are 3 different phases which can be compositionally distinguished by the complementary phase mapping. The uppermost layer (phase 1) is assigned to lubricant layer with abundance of $\mathrm{Na}, \mathrm{B}$ and $\mathrm{O}$ while the two underlying layers are ascertained to oxide matrix (phase 2) and HSS substrate (phase 3), respectively. On the immediate contact interface, localization of $\mathrm{Na}$ is evident in form of a thin film with an estimated thickness of $\sim 50 \mathrm{~nm}$. Simultaneously, O is heavily depleted in this region which certainly alters oxidation behavior of the underneath surface. Upon melting, borate lubricant is considered as an ionic liquid which comprises of highly mobile $\mathrm{Na}$ ions and boron oxide framework. The adsorption of $\mathrm{Na}$ could be triggered by electrostatic interaction between the cations and electron-rich oxidized surface. Low shearing stress of the interfacial film is mainly attributed to the liquid-like state of the lubricant. The interfacial adsorption of $\mathrm{Na}$ on oxide surface was proved essential for lubrication efficiency of borate lubricant [16]. The robust adsorption of $\mathrm{Na}$ allows the tribofilm to sustain high local shearing stress without failure and constantly provide effective lubrication over the whole sliding duration. As a result, the durable lubricant film can act as a physical boundary which ultimately prevents possible segregation of wear debris on the sliding interface. In the circumstances where wear debris is formed, its oxidized surface would be subject to Na adsorption. This would effectively prevent them from being adhered onto the HSS surface due to the repulsion between 2 opposing Na-rich layers. 
a)

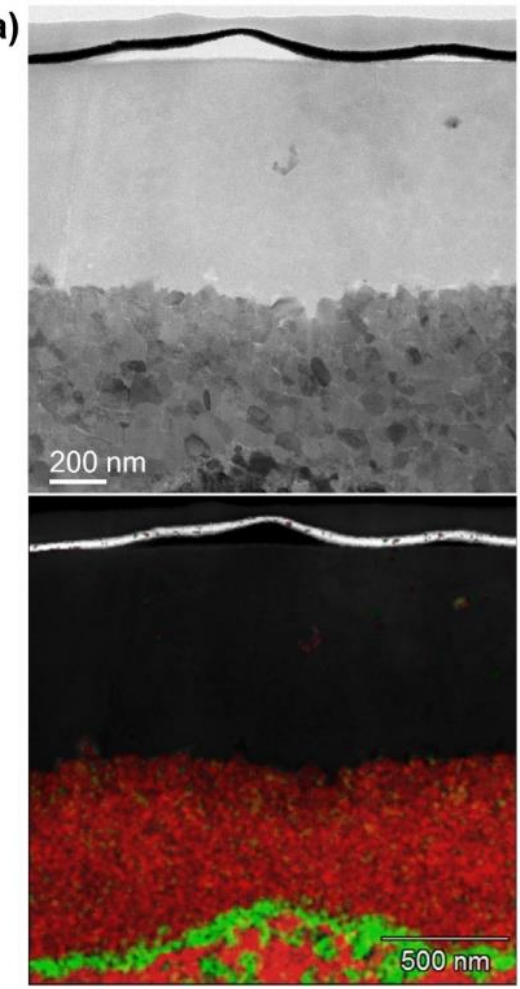

b)

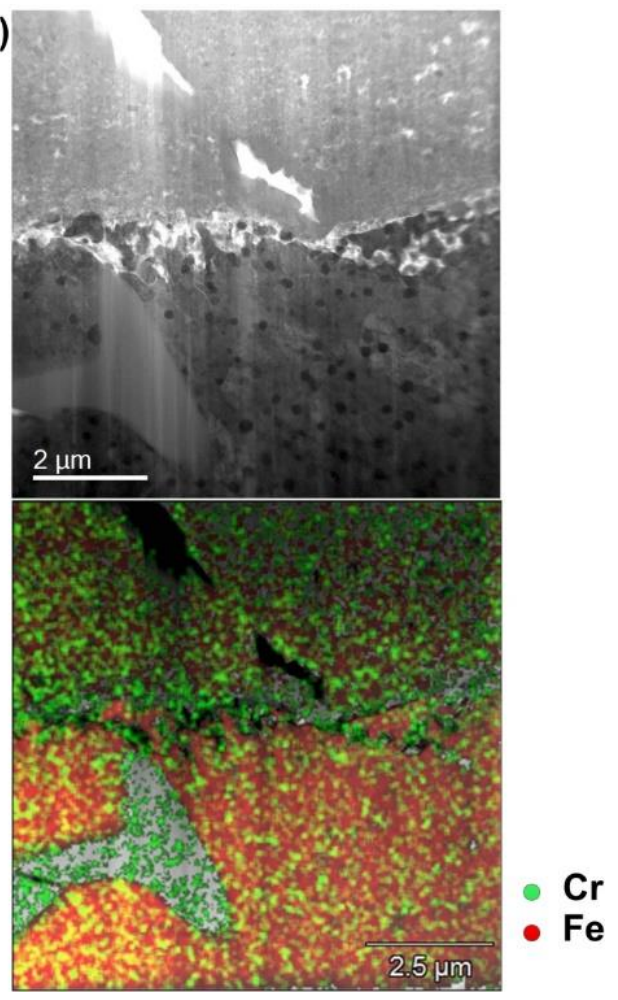

Fig. 15: Localization of Chromia on HSS metal base/scale interface after 5mins lubrication test (a) and its disintegration after 15mins test (b)

As stated previously, steel chemistry also plays a definite role in high-temperature oxidation responses with alloying elements $(\mathrm{Cr}, \mathrm{Al}, \mathrm{Si}, \mathrm{Ni} . .$.$) being introduced to enhance the oxidation resistance$ [30]. Due to their strong affinity with oxygen, oxidation of these sacrificial elements is more thermodynamically favorable with the development of an interlayer oxide [21, 22, 29, 31-34]. Herein, SAED profiles are indicative of Chromia formation in the scales from static oxidation test and 5 mins lubrication test (Fig. 10c and 10a). In addition, Fig. 15a clearly illustrates a highly-localized Chromia film which continuously runs along the scale/substrate interface with a thickness of $100 \mathrm{~nm}$ after 5 mins lubrication test. Formation of $\mathrm{Cr}$ oxides interlayer (and possibly $\mathrm{FeCr}_{2} \mathrm{O}_{3}$ spinel) has been known for inhibiting further oxidation. The compact layer renders low atomic diffusion rate which obstructs the outward migration of $\mathrm{Fe}$ ions. However, prolonged sliding imposes disintegration of Chromia layer as evidenced in Fig. 15b where $\mathrm{Cr}$ signal is found scattering across the scale/base metal interface. The delocalization of Chromia is believed to free outward diffusion of Fe ions which occur along the grain 
boundary [30] and this could result in increased (Fig. 10). Migrating Fe ions appeared to react with the native Hematite to form Magnetite due to limited O activity on the interface (Fig. 14). The resulting internal reduction of Hematite is evidenced by rising proportion of Magnetite (Fig. 10b) with apparent morphology evolution of the oxide nanoparticles (Fig. 11). The reaction route is proposed as Fe (migrating) $+\mathrm{Fe}_{2} \mathrm{O}_{3} \rightarrow \mathrm{Fe}_{3} \mathrm{O}_{4}$ which is greatly facilitated by consistent lubrication effect and continuous tribological exposure on the HSS pin. However, as diffusion of atmospheric O into molten glass is wellacknowledged [35], one could not phase out its potential reaction with Fe ions which can thicken oxide scale over testing time (Fig. 10) despite the fully-formed lubricant film.

The current work used pin-on-disc platform to simulate the sticking occurrence between steel surfaces at high temperature and evaluate the influence of lubrication on such event. In real metal working processes where fresh workpiece is continuously fed into the contact with the tool surface, the extent of sticking depends on many variables (temperature of steel piece, relative speed, steel grade...) and might be different from what observed in laboratory-scale testing. Thus, future work is needed to justify the effectiveness of the concerning lubricant in actual working condition.

\section{Conclusions}

The current work aims to evaluate the effect of lubrication on wear behavior of High Speed Steel at high temperature sliding contact. Also, microstructure evolution of iron oxide under high-temperature lubrication is also discussed. Several conclusions can be made as followed:

- It has been found that HSS surface suffers negligible adhesive/transferred wear under borate lubrication contrary to the unlubricated case. The anti-sticking behavior is closely governed by the tribofilm formation on the immediate sliding.

- Adsorption of alkaline element (herein $\mathrm{Na}$ ) on oxide surface is proved to be not only the foundation for effective lubrication but also the driving force to inhibit material transfer. 
- Prolonged exposure leads to phase transformation of iron oxides in which Hematite was transformed into Magnetite.

\section{Acknowledgements}

This study is funded by Australian Research Council Discovery Project (DP) 150103718. The authors acknowledge the use of facilitates and the assistance of Dr. Mitchel Nancarrow and Dr. David Mitchell in microscopy work. This study used the FEI NanoLab G3 CX funded by the Australian Research Council (ARC) - Linkage, Infrastructure, Equipment and Facilities (LIEF) grant (LE160100063) and JEOL JEMARM200F funded by the Australian Research Council (ARC) - Linkage, Infrastructure, Equipment and Facilities (LIEF) grant (LE120100104) located at the UOW Electron Microscopy Centre. The authors are thankful to the support of Iurii Korobeinikov for viscosity measurement.

\section{References}

[1] Spuzic S, Strafford KN, Subramanian C, Savage G. Wear of hot rolling mill rolls: an overview. Wear. 1994;1994:261-71.

[2] Beynon JH. Tribology of hot metal forming. Tribol Int. 1998;31:73-7.

[3] Pellizzari M, Molinari A, Straffelini G. Tribological behavior of hot rolling rolls. Wear. 2005;259:1281-9.

[4] Belzunce FJ, Ziadi A, Rodriguez C. Structural integrity of hot strip mill rolling rolls. Eng Fail Ana. 2004;11:789-97.

[5] Stott FH. High-temperature sliding wear of metals. Tribol Int. 2002;35:489-95.

[6] Tercelj M, Turk R, Knap M. Assessment of temperature on the die surface in laboratory hot metal forming. Appl Therm Eng. 2003;23:133-25.

[7] Nilsson M, Olsson M. An investigation of worn work roll materials used in the finishing stands of the hot strip mill for steel rolling. Proc Inst Mech Eng J Eng Tribol. 2013;227:838-44. 
[8] Pellizzari M, Cescato D, Flora MGD. Hot friction and wear behaviour of high speed steel and high chromium iron for rolls. Wear. 2009;267:467-75.

[9] Verge C, Boher C, Levaillant C, Gras R. Analysis of the friction and wear behavior of hot work tool scale: application to the hot rolling process. Wear. 2001;250:322-33.

[10] Zhu H, Zhu Q, Tieu AK, Kosasih B, Kong C. A simulation of wear behaviour of high-speed steel hot rolls by means of high temperature pin-on-disc tests. Wear. 2013;302:1310-8.

[11] Cheng X, Jiang Z, Kosasih B, Wu H, Luo S, Jiang L. Influence of Cr-Rich Oxide Scale on Sliding Wear Mechanism of Ferritic Stainless Steel at High Temperature. Tribol Lett. 2016;63:28.

[12] Hao L, Wu H, Wei D, Cheng X, Zhao J, Luo S, et al. Wear and friction behavior of high-speed steel and indefinite chill material for rolling ferritic stainless steels. Wear. 2017;376-377:1580-5.

[13] Pearson SR, Shipway PH, Abere JO, Hewitt RAA. The effect of temperature on wear and friction of a high strength steel in fretting. Wear. 2013;303:622-31.

[14] Tieu AK, Zhu Q, Zhu H, Lu C. An investigation into the tribological behaviour of a work roll material at high temperature. Wear. 2011;273:43-8.

[15] Tran BH, Tieu AK, Wan S, Zhu H, Mitchell DRG, Nancarrow MJ. Multifuntional Bi-Layered Tribofilm Generated on Steel Contact Interfaces under High-Temperature Melt Lubrication. J Phys Chem C. $2017 ; 121: 25092-103$.

[16] Tran BH, Tieu K, Wan S, Zhu H, Cui S, Wang L. Understanding the tribological impacts of alkali element on lubrication of binary borate melt. RSC Adv. 2018;8:28847.

[17] Iwadoh S, Mori T. Effect of Work Roll Materials and Progress of Manufacturing Technology on Cold Rolling and Future Developments in Japan. ISIJ Int. 1992;32:1131-40.

[18] Kim H-H, Lim J-W, Lee J-J. Oxidation Behavior of High-Speed Steels in Dry and Wet Atmospheres. ISIJ Int. 2003;43:1983-8.

[19] Mitchell DRG. Circular Hough transformation diffraction analysis: A software tool for automated measurement of selected area electron diffraction patterns within Digital MicrographTM. Ultramicroscopy. 2008;108:367-74. 
[20] Mitchell DRG. DiffTools: Electron Diffration Software Tools for DigitalMicrographTM. Microsc Res Tech. 2008;71:588-93.

[21] Zhu Q, Zhu HT, Tieu AK, Kong C. Three dimensional microstructure study of oxide scale formed on a high-speed steel by means of SEM, FIB and TEM. Corros Sci. 2011;53:3603-11.

[22] Zhu Q, Zhu HT, Tieu AK, Reid M, Zhang LC. In-situ investigation of oxidation behaviour in highspeed steel roll material under dry and humid atmospheres. Corros Sci. 2010;52:2707-15.

[23] Chen RY, Yuen WYD. Review of the High-Temperature Oxidation of Iron and Carbon Steels in Air or Oxygen. Oxid Met. 2003;59:433-68.

[24] Tian X, Kennedy FE. Maximum and Average Flash Temperatures in Sliding Contacts. J Tribol. 1994;116:167-74.

[25] Smith EH, Arnell RD. A New Approach to the Calculation of Flash Temperatures in Dry, Sliding Contacts. Tribol Lett. 2013;52:407-14.

[26] Verge C, Boher C, Gras R, Levaillant C. Influence of oxides on friction in hot rolling: Experimental investigations and tribological modelling. Wear. 2006;2006:957-75.

[27] Kato H. Severe-mild wear transition by supply of oxide particles on sliding surface. Wear. 2003;255:426-9.

[28] Inman IA, Datta S, Du HL, Burnell-Gray JS, Luo Q. Microscopy of glazed layers formed during high temperature sliding wear at 750oC. Wear. 2003;254:461-7.

[29] Higginson RL, Jepson MAE, West GD. Use of EBSD to characterise high temperature oxides formed on low alloy and stainless steels. Mater Sci Technol. 2006;22:11:1325-32.

[30] Young DJ. High Temperature Oxidation and Corrosion of Metals; Elsevier 2016.

[31] Ha DJ, Lee JS, Kim NJ, Lee S. Effects of Alloying Elements on High-Temperature Oxidation and Sticking Occurring During Hot Rolling of Modified Ferritic STS430J1L Stainless Steel. Metall Mater Trans A. 2012;43A:74-86.

[32] Segerdahl K, Svensson J-E, Johansson L-G. The high temperature oxidation of $11 \%$ chromium steel: Pat I - Influence of pH2O. Mater Corros. 2002;53:247-55. 
[33] Zou D, Zhou Y, Zhang W, Han Y. High temperature oxidation behavior of a high Al-containing ferritic heat-resistant stainless steel. Mater Charact. 2018;136:435-43.

[34] Trindade V, Christ H-J, Krupp U. Grain-Size Effects on the High-Temperature Oxidation Behaviour of Chromium Steels. Oxid Met. 2010;73:551-63.

[35] Bach H, Baucke FKG, Krause D. Electrochemistry of Glasses and Glass Melts, Including Glass Electrodes: Springer-Verlag Berlin Heidelberg; 2001. 